\title{
Studies of Tectonic Motion from Helwan-Satellite Laser Ranging Station
}

\author{
Gamal F. Attia \\ National Research Institute of Astronomy and Geophysics (NRIAG), Cairo, Egypt \\ Email: gamalf.attia@nriag.sci.eg
}

Received 23 September 2014; revised 20 October 2014; accepted 15 November 2014

Copyright (C) 2014 by author and Scientific Research Publishing Inc.

This work is licensed under the Creative Commons Attribution International License (CC BY). http://creativecommons.org/licenses/by/4.0/

(c) (i) Open Access

\begin{abstract}
Satellite Laser Ranging (SLR) is a proven space geodetic technique with significant potential for important contributions to scientific studies of tectonic motion. Currently, SLR is the most accurate available technique to determine the geocentric position with a reported precision in the order of few millimeters. Data gathered through SLR together with "Short Arc" mathematical algorithm became a highly precise tool to detect, monitor and calculate recent crustal movements through repeated measurements of the baselines between some stations on different tectonic plates. In this paper, the Short Arc mathematical model introduced in a previous paper was used to calculate the length of the baseline between Helwan-SLR station and other four fixed SLR stations, placed on different plates. Application of this model with the data gathered through a 4 year time interval gave repeatable results with very high accuracy (in the order of $4 \mathrm{~cm}$ ).
\end{abstract}

\section{Keywords}

Laser Ranging, Laser Radar, Crustal Movements, Short-Arc, Baselines

\section{Introduction}

Geodesy is the science of measurement of the size, shape, rotation, and gravitational field of the Earth.

Plate tectonics is the theory that Earth's outer shell is divided into several plates that glide over the mantle, the rocky inner layer above the core. Tectonic motions are largely slow and smooth in nature, with the exception of regions where earthquake activity is high. In these regions, significant surface displacements over a very short time period can and do occur as shown in Figure 1.

Space geodesy offers a great improvement for all geosciences because scientific observational methods were not limited only on terrestrial techniques, but to satellite ones as well. The main advantages of satellite observational methods are the dense coverage, repeatability and homogeneity of the data offered for almost the entire 


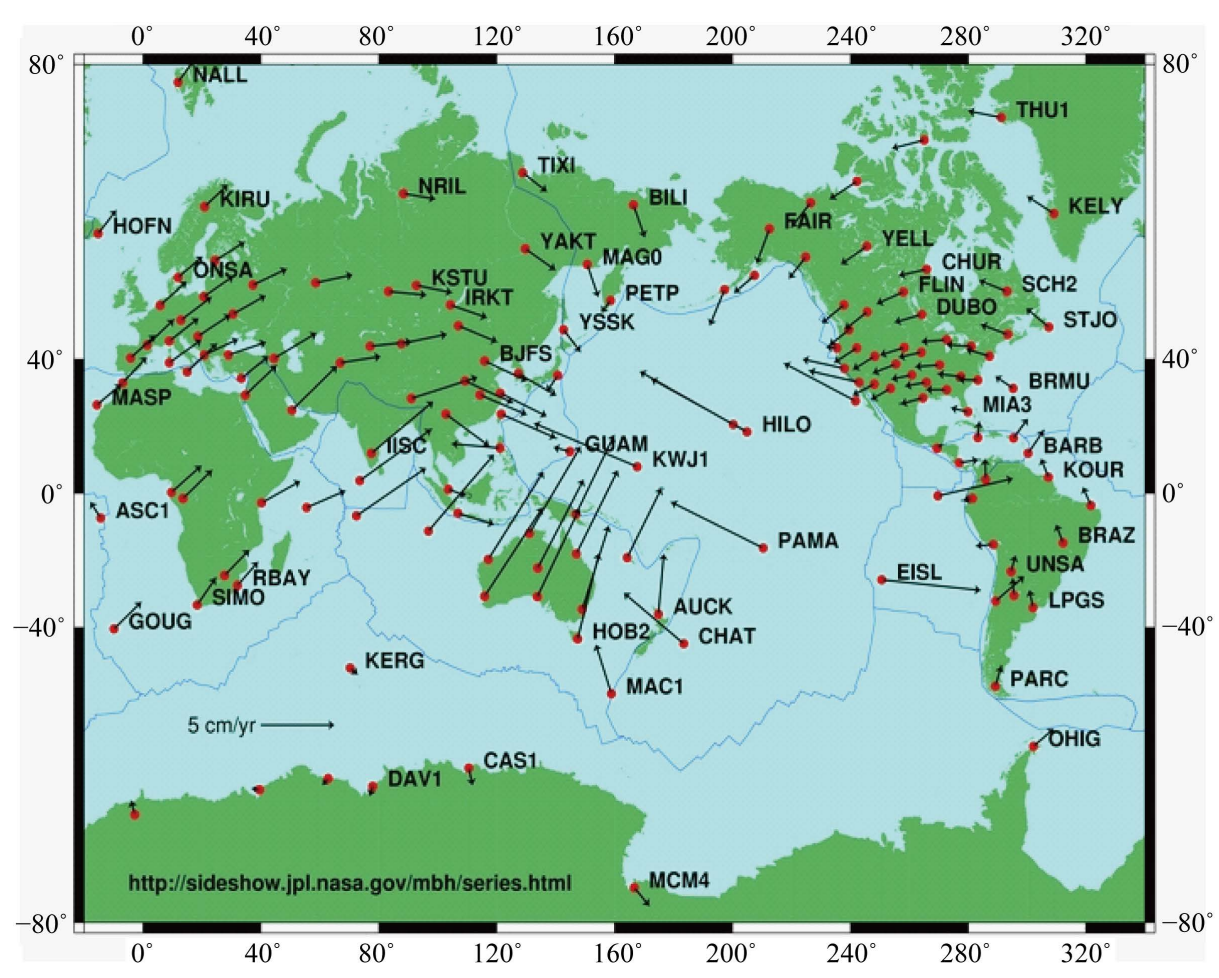

Figure 1. Tectonic motion.

planet. Satellite Laser Ranging (SLR) is one of some space geodetic technologies which can deal with the tectonic motion around the world [1].

The basic idea of Satellite Laser Ranging is measurement of distance between a ground station and a satellite. The ground station transmits a very short laser pulse from a telescope to a satellite which is retro-reflected by corner cube reflectors on the satellite back to the ground telescope. A very precise clock at the ground station measures the round trip time with a very high accuracy ( $<50$ picoseconds, or $<1$ centimeter in range). Measuring the ranges of three satellites of known orbits the position of the station will be calculated.

Methods of space geodesy are very effective in monitoring tectonic motion for points around the world. With over 15 years SLR tracking data acquired by a network of globally distributed stations, shown in Figure 2 variations in station positions can be monitored through time.

The accumulation of the data gives a possibility to construct a precise and detail model of the global tectonics [2].

Geologic features and characteristics of the African continent shows that the African zone is active exhibit all phenomena associated with crustal deformations, accumulation and release of crustal stress and strains, interplate motions as well as volcanic eruptions. Moreover, Figure 2 shows that only two SLR stations are in Africa. These facts illustrate the importance of the data acquired by Helwan SLR station [3].

In this paper, a brief description of Helwan SLR station and the generation technique of the normal points, produced from the analysis of the observed satellites that have a line of sight are discussed.

In one of our previous publications, a mathematical algorithm for the baseline determinations called the shortarc method was introduced and used to calculate the normal point data of satellites Lageos-1, observed during the year 1996, by Helwan SLR [4]. In this paper, the basic concepts of short-arc method is briefly discussed and used to reproduce the normal points of the same satellite as observed during the year 2000 as observed by Helwan SLR. The set of new results are very near to the oldest which proves the repeatability of the technique as a whole over a very long time span.

\section{Helwan SLR-Station}

Tracking of artificial satellites from Helwan SLR station (shown in Figure 3) has been started in 1974. A lot of 


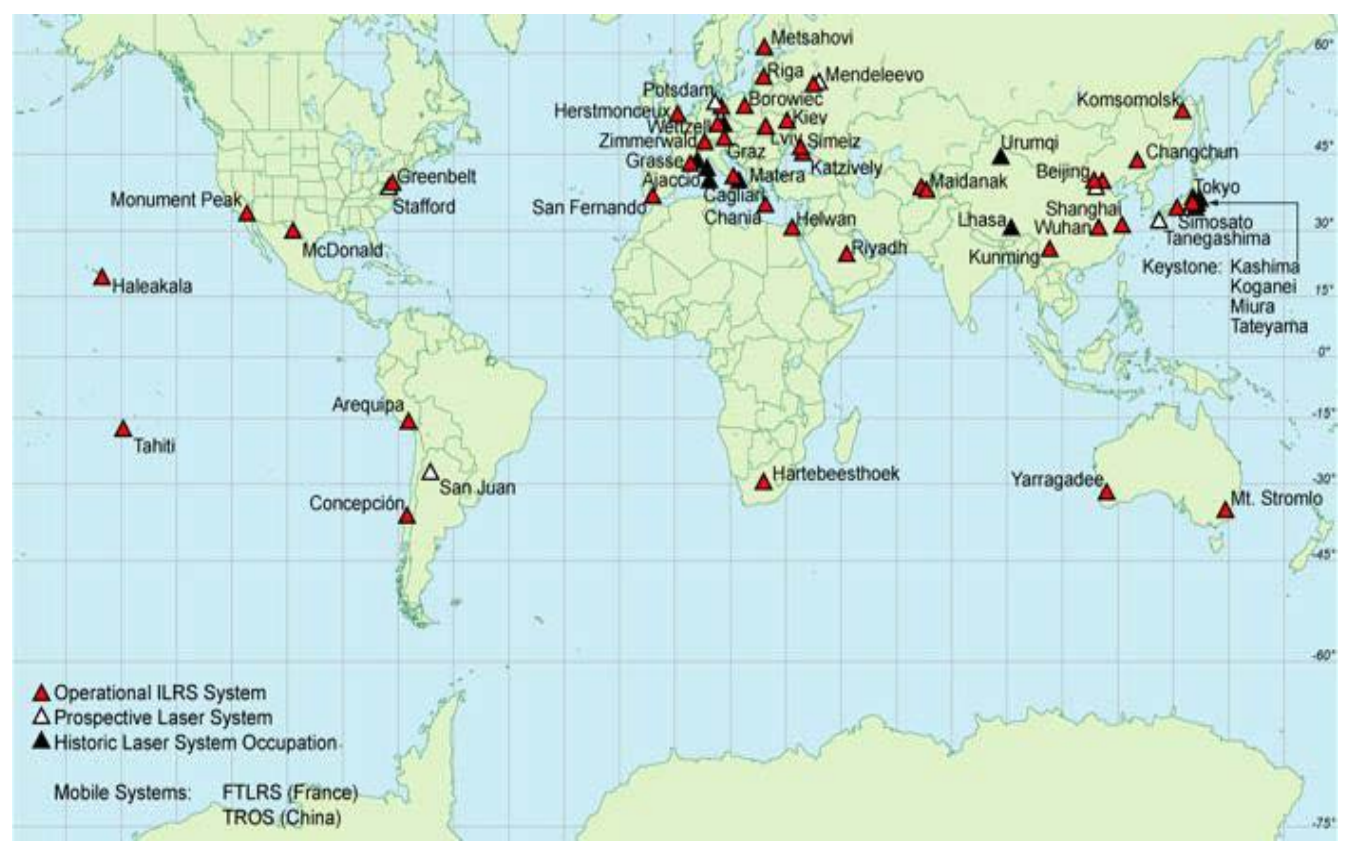

Figure 2. The SLR global network.

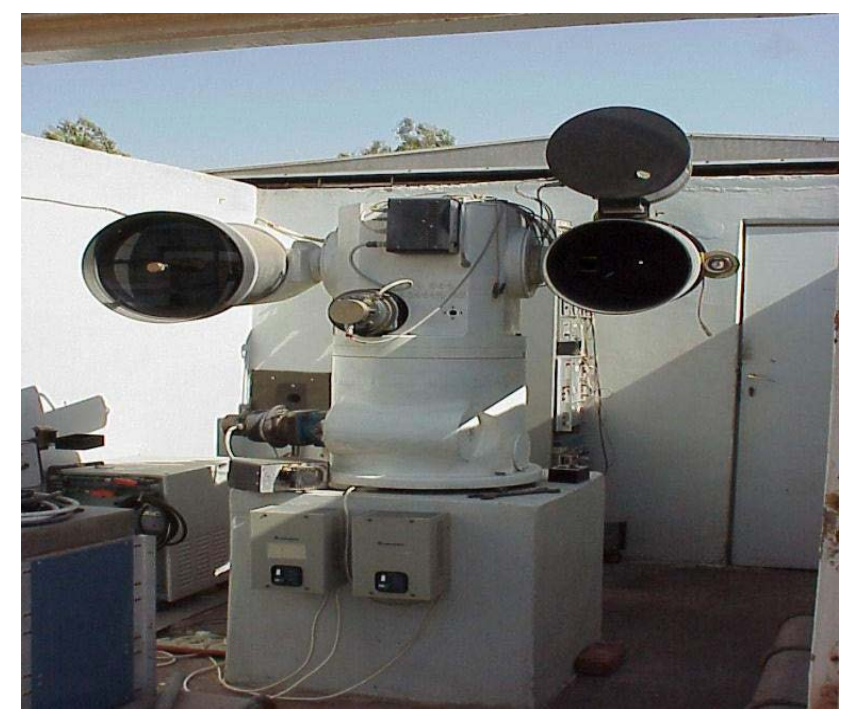

Figure 3. Helwan SLR station.

modifications have been applied to the station in order to improve its accuracy and update its performance [5]-[12]. Next; the main components and specifications of Helwan SLR station are summarized.

The mount configuration is Azimuth/Elevation with a coude system of mirrors for the transmitted beams. The movement drive is consisting of 2 step drive motors, and the maximum tracking rate is 2 deg./sec. The guiding of the mount is controlled by a computer. The receiving system of the mount is a spherical mirror of diameter 40 $\mathrm{cm}$, and optical filter of $6 \mathrm{~nm}$ with $80 \%$ transmission. The type of the detector is a Photomultiplier manufactured by Hamamatsu model H6533. The quantum efficiency of this PMT is $10 \%$ at $532 \mathrm{~nm}$ and of normal gain equal 5.6 million. The mode of the PMT is single photoelectron detection. The detailed specifications of Helwan SLR station are summarized in Table 1.

The laser transmitter is placed outside the mount and the laser beam is directed to the satellite through the mount via a four coude of mirrors. The time and frequency system is GPS Time/Frequency standard, manufactured by Helwlett-Packard of model 58503B, and it measures the time with accuracy below than 110 nsec. The 
Table 1. Main specifications of the Helwan-SLR station.

\begin{tabular}{ll}
\hline Subsystem & Specification \\
\hline Laser & \\
Oscilator & Mode locked Nd:YAG with 3 amplifier systems \\
Wavelength & $532 \mathrm{~nm}$ \\
Output energy & $80 \mathrm{~mJ}$ \\
Pulse width & $20 \mathrm{ps}$ \\
Repetition rate & $5 \mathrm{pps}$ \\
Beam divergence & from 0.2 mrad to 0.1 mrad (adjustable) \\
Mount & \\
$\quad$ Configuration & Azimuth/elevation with coude path \\
Transmitter/Receiver Optics & \\
Telescope & Galilean for transmitter and Keplarian for receiver \\
Diameter & 25 cm for transmitter and 40 cm for receiver \\
Electronics & \\
Start detector & Photodiode with 200 ps rise time \\
Receiving detector & PMT H6533 with 300 ps rise time \\
Jitter (single PE) & 30 ps \\
Time interval counter & 4 ps of resolution \\
\hline
\end{tabular}

meteorological station (MET-3) is installed to improve temperature, humidity and atmospheric pressure's measurements.

\section{Satellite LAGEOS-1}

Laser Geodynamics Satellites-1 (LAGEOS-1) is a satellite designed to provide an orbiting benchmark for geodynamical studies of the Earth. Figure 4 shows the LAGEOS-1 satellite

LAGEOS-1 is able to determine positions of points on the Earth with extremely high accuracy due to the stability of its orbit. The main specifications of LAGEOS- 1 are given in Table 2.

\section{Normal Points Computed Using Helwan-SLR Data}

The primary output of the satellite laser ranging stations is the normal point data. For the generation of the normal points, it is agreed that the values of the bins size to be as $15 \mathrm{sec}$ for some satellites such as Becon-C Topex, GFO-1, ERS-2 and Champ. For some other satellites such as Ajisai, Starlette and Stella, the value of the bin size is $30 \mathrm{sec}$. As for the satellites Lageos-1 it is agreed to be $120 \mathrm{sec}$. After the observations of the satellites, the satellite pass is analyzed [7] [8] and hence the normal points are computed for each pass depending on the bin size mentioned before. Data observed for the satellite LAGEOS-1 was used to compute normal points as given in Table 3.

Data include 9 normal points as indicated in the first Column. The second third and fourth columns are the time of which the normal points are selected. The fifth and sixth columns are the corresponding range, the seventh and eighth columns the corresponding precision of each normal point resp. The last column contains the number of points included in each normal point.

\section{Baseline Determination Using the Short-Arc Method}

The baselines are the distances and lengths of the chords between projections of the positions of the laser stations on the reference ellipsoid. For the satellite geodesy, it is very important to determine the optimal length of orbital arc along which laser measurements are to be carried out. It is clear that for the dynamical methods long arcs (one month or more) are to be used. According to which more errors of modeling of different physical 


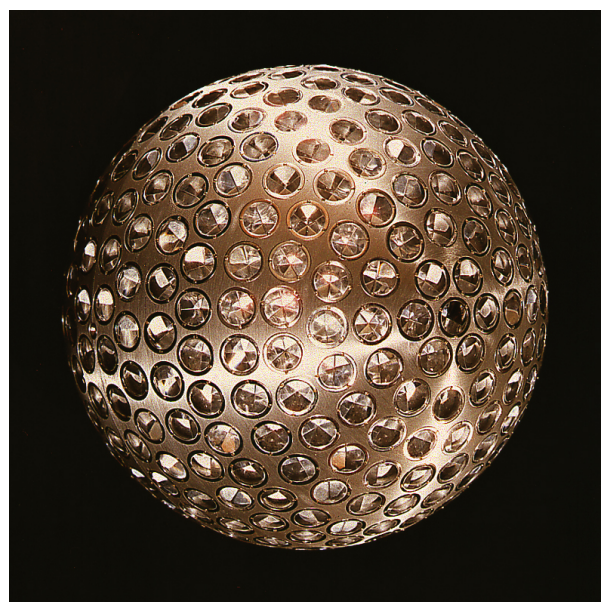

Figure 4. The LAGEOS-1 satellite.

Table 2. Major specifications of the satellite Lageos-1.

\begin{tabular}{cl}
\hline Configuration & An aluminum alloy sphere with inner core of uranium 238 \\
\hline Diameter & $60 \mathrm{~cm}$ \\
Weight & $400 \mathrm{~kg}$ \\
Laser reflector & 426 cube corner reflector (422 of silica and 4 of germanium) \\
Orbit & Perigee: $810 \mathrm{~km}$, Apogee: $1105 \mathrm{~km}$ and inclination: $49.8 \mathrm{deg}$ \\
Lunch & Feb. 1975 \\
\hline
\end{tabular}

Table 3. Normal point as computed for the satellite LAGEOS.

\begin{tabular}{ccccccccc}
\hline Ser. & h & $\mathbf{m}$ & sec & Range (ms) & Range (Km) & Precision (psec) & Precision (mm) & PT/NPT \\
\hline 1 & 23 & 40 & 54.600286 & 43.96340609 & 6589.948786886630 & 212.9 & 31.91290715410 & 6 \\
2 & 23 & 43 & 1.6002874 & 43.32414997 & 6494.126705133460 & 166.6 & 24.97271175140 \\
3 & 23 & 44 & 16.600284 & 43.09372337 & 6459.586626732170 & 176 & 26.38173630400 & 1 \\
4 & 23 & 46 & 0.0002876 & 42.95974443 & 6439.503688860750 & 176 & 26.38173630400 & 1 \\
5 & 23 & 48 & 3.2002864 & 43.08019537 & 6457.558830546260 & 176 & 26.38173630400 \\
6 & 23 & 53 & 52.800289 & 45.0202523 & 6748.366048398580 & 176 & 26.38173630400 \\
7 & 23 & 54 & 41.000293 & 45.45943131 & 6814.197325853530 & 176 & 26.38173630400 & 1 \\
8 & 23 & 57 & 46.200301 & 47.48417843 & 7117.699283820140 & 95.9 & 14.37504836110 \\
9 & 23 & 59 & 38.40029 & 48.94468536 & 7336.623765055510 & 204.9 & 30.71373732210 & 4 \\
\hline
\end{tabular}

forces such as earth's gravitational field, air drag, solar radiation pressure, and others that may influence the accuracy of the estimation of the satellites position, at the same time the measured errors con be almost completely excluded and high stability in determination of relative coordinate system can be achieved. It is possible to diminish the influence of the errors of modeling by using short-arcs of the satellite orbit (several revolutions or days), but the station's coordinates estimated by different arcs con differ from each other by a larger quantity than statistical zero.

Under the semi-dynamical "short-arc" method one or several passes of the satellite in one of simultaneous visibility from both ends of the chord is known [13]-[16]. The estimated parameter in this case is the length of the chord as shown in Figure 5.

The comparison of the same baselines calculated with long and short arcs methods shows a good agreement and even speaks in favor of the last one, as the number of observations required for solving the problem considerably decreases the amount of calculations. Detailed analysis of short-arc method was introduced in one of our previous publications [5]. 


\section{Results and Discussions}

A computer program was implemented for baselines calculations using the short-arc method and observational data of LAGEOS-1 during the year of 2000 as measured by Helwan SLR station and other SLR stations. The stations used in addition to the Helwan SLR station (7831) are, Heslmonseux (7840), Zimmerworld (7810), matera (7939) and Grasse (7835) as shown in Figure 4. The short arc method does not depend on the dynamical models so strongly. However in order to realize millimeter level baseline precision.

The results of the normal point's data, of satellites LAGEOS-1, observed at year 2000, are used to estimate 4 different baselines. The baselines between the Helwan station and the other stations are computed and the results are shown in Table 4. The first column represents the ID of the used station with Helwan station, column 2 represents the used time in modified julean date, column 3, represents the value of the baseline length in meter units, as for the last column shows the root mean square value of the measurements. Results show that the root mean square errors of the calculated baselines are within $4 \mathrm{~cm}$.

For determination of the relative motion between the African and European plates, it is necessary to calculate the same baselines for many years. The next 3 columns of Table 4 show the same results calculated using the data observed at year 1996 and the same algorithm. The observed motions, both in the case of year 2000 and year 1996 data are in good agreement with each other.

\section{Conclusion}

Observational data measured by Helwan Satellite Laser Ranging station, for the satellite Lageos-1, were used to

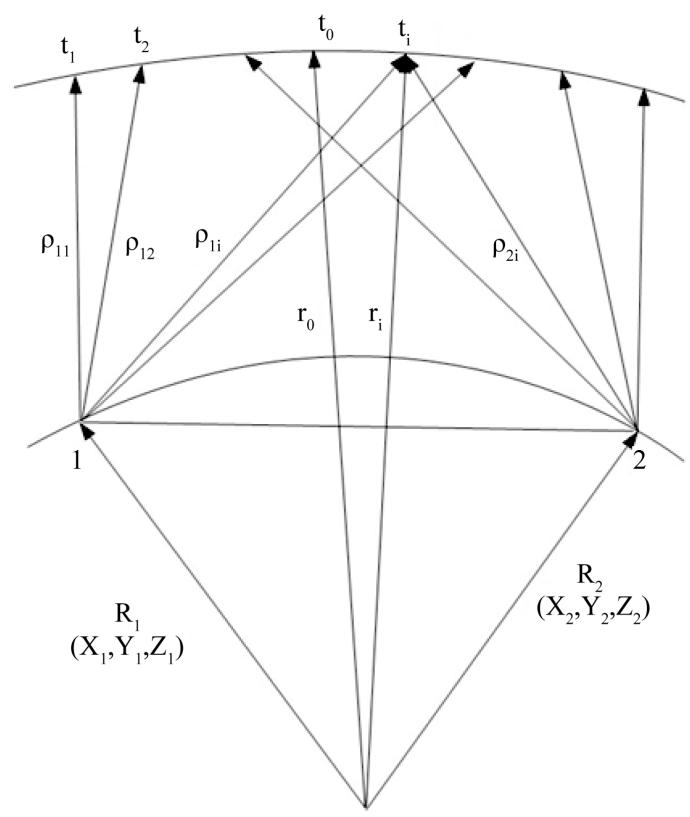

Geocenter

Figure 5. Geometrical representation of short-arc method.

Table 4. Baselines determinations between Helwan SLR station and some other SLR stations.

\begin{tabular}{ccccccc}
\hline \multirow{2}{*}{ Station } & \multicolumn{3}{c}{ Data observed at year 2000 } & \multicolumn{3}{c}{ Data observed at year 1996 } \\
\cline { 2 - 7 } & MJD & Baseline length L (m) & RMS (m) & MJD & Baseline length L (m) & RMS (m) \\
\hline $7831-7840$ & 2451724.336 & 3429766.4165 & 0.038 & 50266.784425 & 3429766.4070 \\
$7831-7810$ & 2451851.377 & 2771788.8283 & 0.035 & 50264.754674 & 2771788.8583 \\
$7831-7939$ & 2451630.586 & 1780653.3729 & 0.021 & 50264.757669 & 1780653.3904 \\
$7831-7835$ & 2451849.486 & 2634229.0949 & 0.032 & 50266.795464 & 2634229.0854 \\
\hline
\end{tabular}


measure Tectonic motion with very high accuracy. The "short-arc" modeling technique was introduced for the determination of the baselines between Helwan Satellite Laser Ranging station (7831) and, Heslmonseux SLR (7840), Zimmerworld SLR (7810), matera LSR (7939) and Grasse LSR (7835) placed on different plates. The data observed by Helwan SLR station the years of 1996 and 2000 were used to calculate the base line and the relative motion between the African and European plates. Results show repeatability with a very high accuracy for plate motions (in the order of $4 \mathrm{~cm}$ ).

\section{References}

[1] Torsvik, T.H., Müller, R.D., van der Voo, R., Steinberger, B. and Gaina, C. (2008) Global Plate Motion Frames: Toward a Unified Model. Reviews of Geophysics, 46, Article ID: RG3004. http://dx.doi.org/10.1029/2007RG000227

[2] Pindell, J.L. and Kennan, L. (2009) Tectonic Evolution of the Gulf of Mexico, Caribbean and Northern South America in the Mantle Reference Frame: An Update. In: James, K., Antonieta-Lorente, M. and Pindell, J., Eds., The Geology and Evolution of the Region between North and South America, Geological Society of London, London, 227-242.

[3] Zerbini, S. (1992) Crustal Motion from Short-Arc Analysis of the LAGEOS Data. In: Smith, D.E. and Turcotte, D.L., Eds., Contributions of Space Geodesy in Geodynamics: Crustal Dynamics, AGU Geodynamics Series, 371-388. http://dx.doi.org/10.1029/GD023p0371

[4] Reilinger, R., McClusky, S., Vernant, P., et al. (2006) GPS Constraints on Continental Deformation in the Africa-Arabia-Eurasia Continental Collision Zone and Implications for the Dynamics of Plate Interactions. Journal of Geophysical Research, 111. http://dx.doi.org/10.1029/2005JB004051

[5] Attia, G.F., Hegazy, M.A. and Abd El-Hameed, A.M. (2012) The Use of Satellite Laser Observations in Studying the Crustal Movements. NRIAG Journal of Astronomy and Geophysics, 1, 110-113. http://dx.doi.org/10.1016/j.nrjag.2012.12.006

[6] Cech, M., Hamal, K., Jelinkova, H., Novotny, A., Prochazka, I., Helali, Y.E. and Tawadros, M.Y. (1998) Upgrading of the Helwan Laser Station (1997-98). Proceedings of the 11th International Workshop on Laser Ranging, Deggendorf, 21-25 September 1998, 197.

[7] Ibrahim, M., Tawadros, M.Y., Helali, Y.E., El-Saftawy, M., Fahim, G. and Hanna, Y.S. (2001) Results of on Site Data Processing after Upgrading of Helwan SLR Station. Bulletin of National Research Institute of Astronomy and Geophysics, Series A, 1, 51-67.

[8] Fahim, G. (2003) Improvments of the Accuracy at Helwan Satellite Laser Tracking Station. NRIAG Journal of Astronomy and Geophysics, 2, 47-63.

[9] Ibrahim, M. (2005) Ranging to New Satellites from Helwan Laser Tracking Station. Journal of the Astronomical Society of Egypt, 13, 52.

[10] Jelinkova, H. (1984) Mode Locked Train Laser Transmitter. Proceedings of the 5th International Workshop on Laser ranging Instrumentation, Geodetic Institute, Universität Bonn, Herstmonceux, 224.

[11] Ibrahim, M., Abd Elhameed, A.M. and Attia, G.F. (2011) Analytical Studies of Laser Parameters for Ranging and Illuminating Satellites from H-SLR Station. Space Research Journal, 4, 71-78.

[12] Prochazka, I. (1989) Mode Locked Semitrain Laser Ranging Data Processing Soft Ware. Proceedings of the 7th International Workshop on Laser Ranging Instrumentation, Matera, 2-8 October 1989, 405.

[13] Dictrch, R. and Genill, G. (1984) Determination of Regional Networks for Geodynamical Studies Based on Satellite Laser Ranging Data. Bulletin of Russian Institute of Astronomy, No. 21, Part 2, 38-49.

[14] Chapanov, Ya. G. and Tatevian, S.K. (1990) Determination of Long Baselines with a Short-Arc Techniques. Proceedings of the Intercosmos Laser Workshop, Riga, 15-17 March 1990.

[15] Tatevian, S.R. (1980) Possibilities of Short Arc Techniques for the Estimation of the cords between Two Stations. Scientific Information of the Astronomical Council, 12.

[16] Saroken, N.A., Abrekosov, O.A. and Marchenko, A.N. (1984) The Use of the Improving Models for the Salellite's Orbit. Bulletin of Russian institute of Astronomy No. 21, 17-29. 
Scientific Research Publishing (SCIRP) is one of the largest Open Access journal publishers. It is currently publishing more than 200 open access, online, peer-reviewed journals covering a wide range of academic disciplines. SCIRP serves the worldwide academic communities and contributes to the progress and application of science with its publication.

Other selected journals from SCIRP are listed as below. Submit your manuscript to us via either submit@scirp.org or Online Submission Portal.
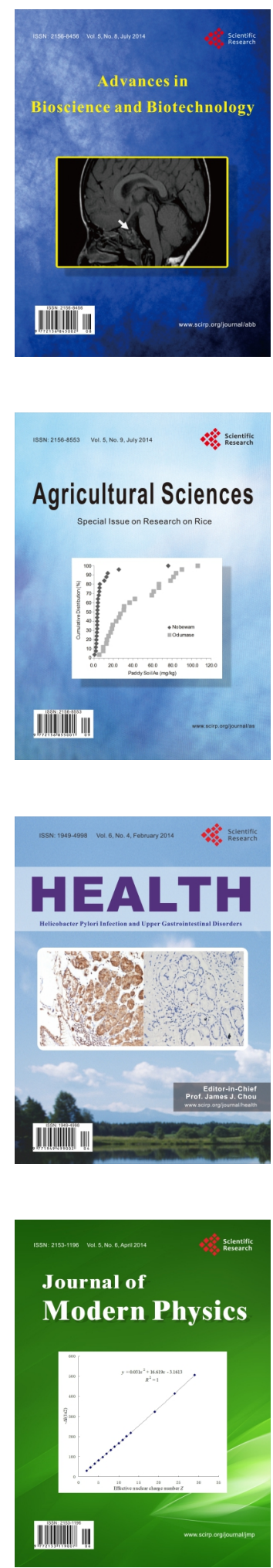
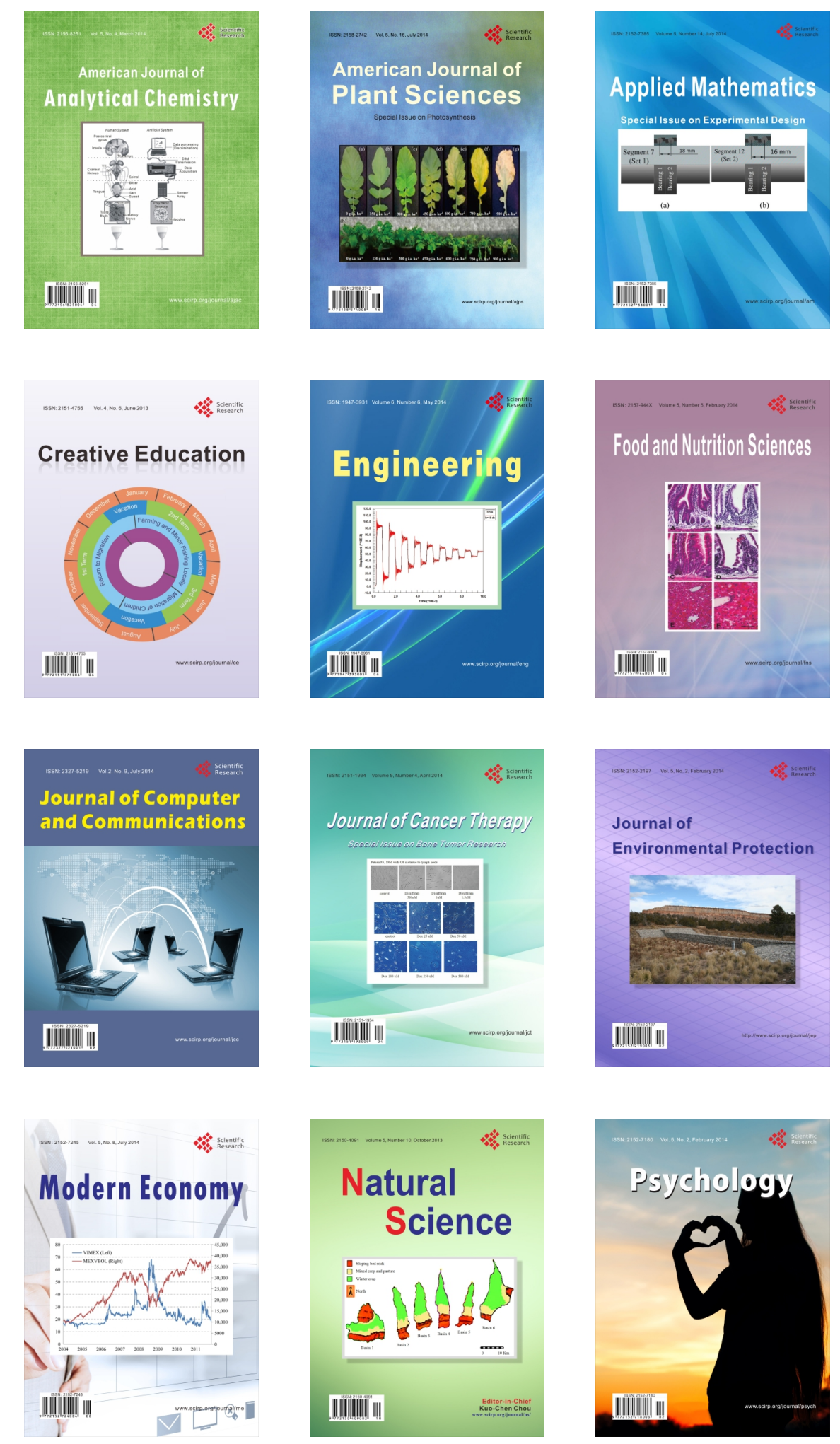